Психология. Журнал Высшей школы экономики,

2020. T. 17. № 4. C. 737-756. DOI: 10.17323/1813-8918-2020-4-737-756

\title{
ПСИХОСЕМАНТИЧЕСКИЙ АНАЛИЗ ХУДОЖЕСТВЕННОГО ФИЛЬМА АКИРЫ КУРОСАВЫ «РАСЁМОН»
}

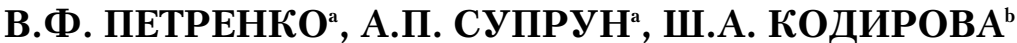

\author{
${ }^{a}$ Московский государственный университет имени М.В. Ломоносова, 119991, Россия, Москва, \\ Ленинские горы, 1 \\ ${ }^{b}$ Академия государственного управления при Президенте Республики Узбекистан, 100066, \\ узбекистан, г. Ташкент, ул. Ислама Каримова, д. 45
}

\begin{abstract}
Резюме
Настоящая статья посвящена психосемантическому анализу художественного фильма «Расёмон» японского режиссера Акиры Куросавы, снятого по мотивам рассказов «В чаще» и «Ворота Расёмон» Рюноскэ Акутагавы. Научные идеи в различных формах часто вызревают на уровне коллективного и индивидуального бессознательного. Так, создатель теории относительности Альберт Эйнштейн отмечал, что креативным аналогом теории относительности для него стал роман Ф.М. Достоевского «Братья Карамазовы». Согласно понятию «полифонизм», введенному М.М. Бахтиным, голоса персонажей Достоевского выступают как самостоятельные системы отсчета, несущие свою правду жизни. Аналогично в теории А. Эйнштейна параметры наблюдаемого объекта зависят от позиции наблюдателя и нет какого-то «правильного» описания» вне этой позиции. Н. Бор считал, что как исследуемому явлению, так и его наблюдателю нельзя приписать самостоятельную физическую реальность. В эвереттовской (многомировой) трактовке квантовой механики вводится понятие соотнесенного состояния («relative state»), возникающего при наблюдении квантовой системы. Х. Эверетт считал, что результатом ее наблюдения является не «мистическая» редукция всех возможностей к единственной, а расщепление реальности на множество миров, где реализуется одна из этих возможностей. Сейчас в эвереттике считается, что результатом наблюдения является альтерверс - некоторая совокупность состояний, где единая реальность наблюдается с различных «точек зрения». Отметим, что еще Сократ показал условность или относительность любого эмпирического познания мира. Заставляя собеседников прилагать «общие для всех» понятия к различным предметам, он вынуждал их прийти к пониманию того, что эти предметы становятся иллюзорными, т.е. не соответствующими этим «единым» понятиям. Наш интерес к проблеме влияния позиции наблюдателей на конструируемую ими реальность отражен в серии публикаций на данную тему. И в этом контексте нас привлек фильм «Расёмон», в котором идеи релятивизма контрастно представлены в художественной форме.
\end{abstract}

Ключевые слова: киноискусство, психосемантика, семантические пространства, многомерность истины, релятивизм.

Исследование выполнено при поддержке РФФИ, проект № 19-013-00603. 


\section{Фабула фильма}

Самурай и его молодая жена проезжают через незаселенную лесистую местность и встречаются с разбойником. Очарованный красотой жены самурая, он решает овладеть ею. Хитростью, используя алчность самурая, он уводит его от жены подальше в лес и, напав, связывает. Связанный самурай вынужден наблюдать, как разбойник насилует его жену. Опозоренная жена самурая требует от мужчин, чтобы они вступили в схватку друг с другом, обещая остаться с победителем. Дальнейшие события излагаются с позиции четырех участников и наблюдателей, описывающих происшедшее в четырех разных версиях.

Версия 1. Пойманный разбойник рассказывает на суде, что жена самурая потребовала от него убить ее мужа, свидетеля ее бесчестия. Но разбойник, потрясенный вероломством женщины, предпочел разрешить ситуацию в честном поединке. Он рассказывает, как они с самураем храбро сражались и как он в бою убил самурая своим мечом.

Версия 2. Жена самурая, подавленная случившимся, описывает, как была потрясена полным презрением мужа по отношению к ней после ее изнасилования и как, не выдержав его холодного взгляда, в полубредовом бессознательном состоянии заколола его женским кинжалом.

Версию 3 излагает дух погибшего самурая, вызванный с помощью шаманки-прорицательницы. Согласно версии духа самурая, его любимая жена после всего случившегося заявила разбойнику, что хочет остаться с ним, но оговорила условие - убийство ее мужа как свидетеля. Вероломство женщины потрясло даже разбойника, и он, с презрением прогнав женщину, освободил самурая. Самурай же, потерявший честь и жену, свершает самоубийство с помощью брошенного женского кинжала, сохранив тем самым верность самурайскому кодексу чести.

Версия 4. Рассказ дровосека, оказавшегося нечаянным свидетелем происшествия, о том, как жене самурая удалось освободить мужа, перерезав кинжалом веревки, его связывающие. Но самурай уклонился от боя с разбойником, сказав, что опозоренная жена ему не нужна. Оскорбленная жена самурая высмеяла обоих мужчин, обвинив в трусости и сказав, что мужчины должны добиваться женщины мечом, тем фактически принудив их к поединку. В результате неумелой схватки перепуганных участников разбойник мечом убил самурая.

В задачу исследования входила реконструкция понимания зрителями замысла и смысла художественного фильма.

Метод исследования включал выделение личностных конструктов с использованием техники триадического выбора Дж. Келли (2000) и построение семантического пространства персонажей фильма. Подробно данная процедура описана в серии публикации по психосемантическому анализу киноискусства (Петренко, 2013; Петренко и др., 1982; Грачева и др., 1988; Петренко, Сапсолева, 2005; Петренко, Дедюкина, 2017, 2018), в настоящей статье мы ограничимся представлением читателю результатов построения 
семантических пространств персонажей фильма. Кроме того, мы приводим выдержки из объяснений испытуемыми смысла этого художественного фильма.

Процедура исследования. Испытуемые - 20 учащихся магистратуры МГУ (11 москвичей и 9 ташкентцев) методом триадического выбора на материале персонажей фильма «Расёмон» (самурай, жена самурая, разбойник, дровосек, буддийский монах, вор-провокатор, а также ролевые позиции «я-сам» и «мой идеал») формировали личностные конструкты персонажей фильма. В отличие от метода семантического дифференциала, оценочные шкалы создаются самими испытуемыми в рамках триадического шкалирования путем сопоставления персонажей. Таким образом испытуемые выступают соавторами исследователей, и от уровня их рефлексии, от их таланта, от их способности выявить особенности личности персонажей и дать креативную интерпретацию их поступков, выраженную в шкалах оценки, зависят мерность (когнитивная сложность) выстраиваемого семантического пространства и глубина понимания художественного произведения. На основе выделенных конструктов, выступающих биполярными шкалами, испытуемые должны были оценить по семибалльной шкале $(3,2,1,0,-1,-2,-3)$ всех персонажей фильма. Полученная матрица данных (9 ролевых позиций $\times 49$ шкал) подвергалась процедуре факторного анализа центроидным методом (Окунь, 1974).

В результате факторной обработки данных «по личностным конструктам» было выделено 4 значимых фактора, объясняющих соответственно 66.1; 17.3 ; $6.7 ; 4.3 \%$ общей дисперсии. Интерпретация и называние факторов осуществляются на основе выделения смыслового инварианта шкал (личностных конструктов), имеющих высокую нагрузку по выделенным факторам.

По первому фактору наибольшую нагрузку имели следующие характеристики (в порядке уменьшения веса факторных нагрузок): «направленный на совершение доброго деяния», «высокие жизненные ценности», «доброта», «чувство справедливости», «благородный», «ищущий правду», «вера в людей и искренность», «считающий все земные блага отвлекающими от настоящей сути человека» и др.; в оппозиции: «ищущий в любой ситуации способ извлечения выгоды», «беспечность», «злость», «безразличие», «идет по головам для достижения целей», «склонный ко лжи», «оборачивающий ситуацию в свою выгоду», «с легкостью пренебрегает ценностями», «не способный удерживать (контролировать) свои влечения» и другие, имеющие большие нагрузки с другим знаком. Исходя из семантики вышеперечисленных пунктов, вошедших в данный фактор, первый фактор был назван «Высокая моральная нравственность - Отсутствие духовности (потребительская позиция)».

Во второй фактор вошли такие личностные качества (в порядке уменьшения веса факторных нагрузок): «высшее общество», «признанный статус в обществе», «пытается оправдать свои поступки», «заинтересованный выглядеть лучше перед обществом», «ведут жизнь по привычным социальным нормам», «боится осуждения окружающих», «подверженность социальным нормам», «нежелание принять ответственность за собственный поступок»; в оппозиции: «простолюдины», «низкое положение», «открыто признает свою 
Семантическое пространство по первому и второму факторам

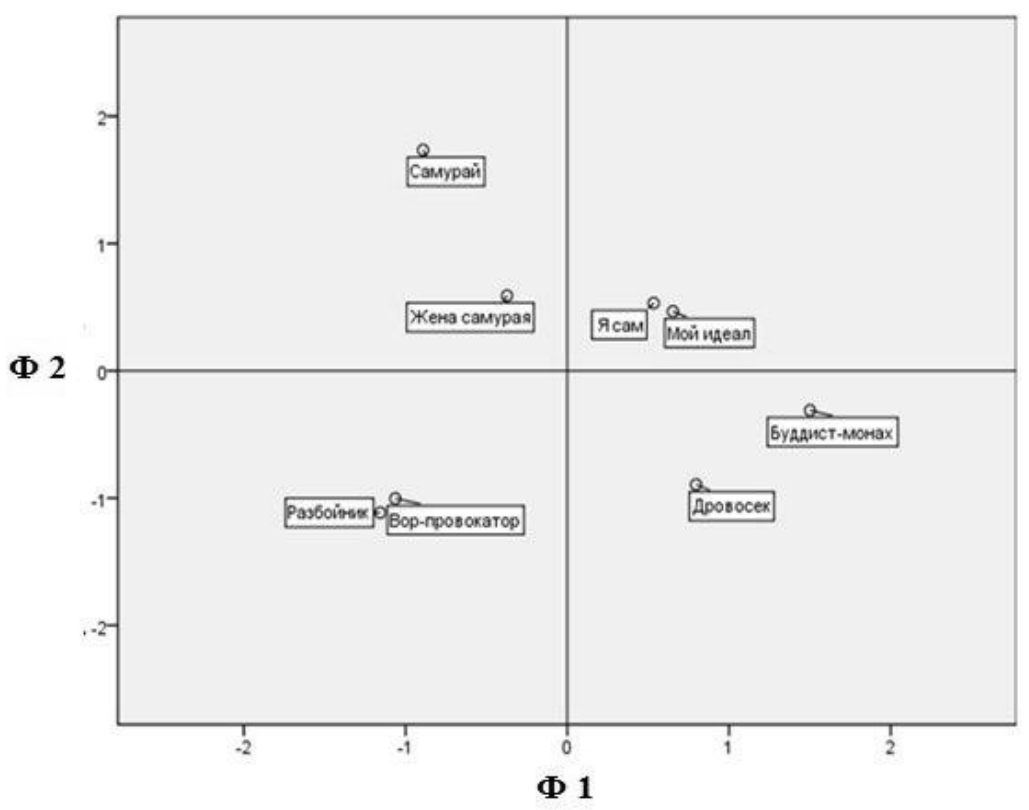

непорядочность», «не считающий мнение общества как ценность», «ведет жизнь отшельника», «безразличен к неэтичности своего поступка» и т.п. Данный фактор может быть интерпретирован как «Высокий социальный статус - Низкий социальный статус» (см. рисунок 1).

Перейдем к следующему семантическому пространству, построенному по третьему и четвертому факторам: «Слабость личности - Сила личности» и «Субъект своего бытия - Пассивная жертва» (см. рисунок 2).

Третий фактор включал характеристики: «смелость», «не боится трудностей», «активный человек», «активная позиция в инициации и исполнении собственных потребностей»; в оппозиции: «избегание трудностей», «быстро отрекается от своих принципов», «пассивный», «безучастная поведенческая позиция». Сгруппированные качества, по-видимому, отражают, с одной стороны, поведение героев фильма, выражающих «стремление к успеху», которое в процессе жизнедеятельности кристаллизуется и превращается в некий «стержень» личности, с другой стороны, показывает людей со статусом «избегание неудач», который, в свою очередь, оборачивается в некую хилость личности. Третий фактор был назван «Сила личности - Слабость личности».

Четвертый фактор включает следующие конструкты: «жертва», «принимает решение других людей относительно своей судьбы»; в оппозиции «наблюдатель», «имеет право выбирать самостоятельно». Группировка данных переменных, вероятно, также была спровоцирована разграничением в просмотренном кинофильме людей способных, имеющих право самостоятельно 
Семантическое пространство по третьему и четвертому факторам

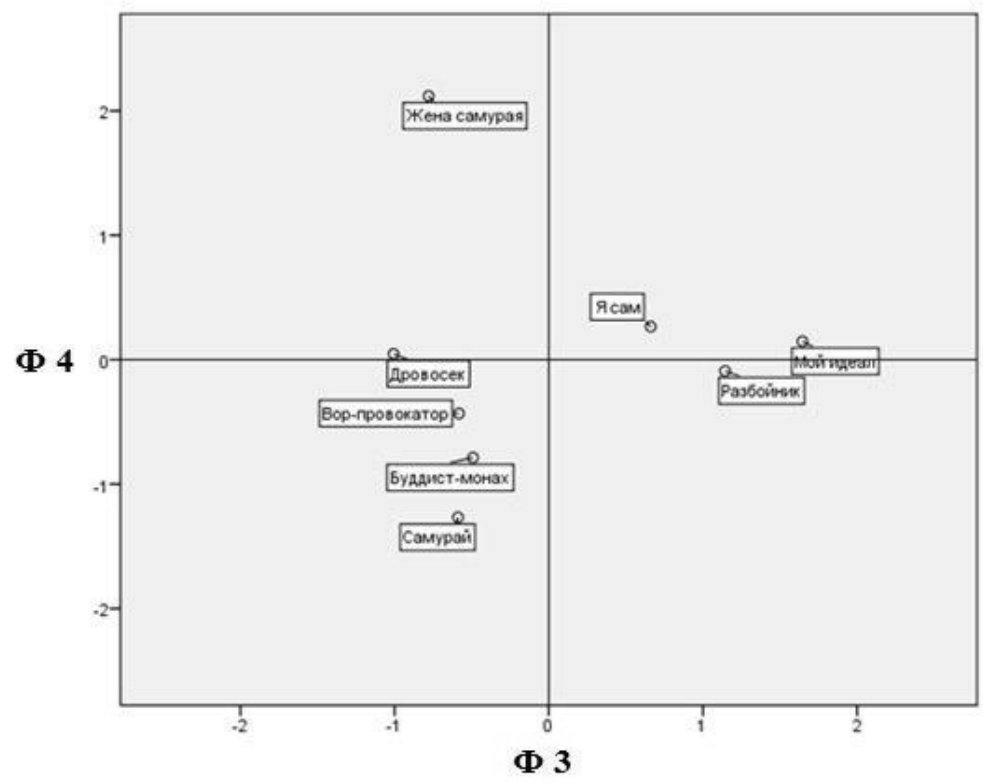

действовать и принимать решения, и людей, которые целиком и полностью находятся под властью вышестоящего человека. Это, в свою очередь, дало название данному фактору «Пассивная жертва - Субъект своего бытия».

Как видим, типовой семантический анализ в рамках системы личностных конструктов мало что дал для понимания смысла фильма. Испытуемыемагистры при выделении личностных конструктов ограничились чисто индивидуальными и социальными характеристиками персонажей, что во многом обусловлено спецификой метода выделения личностных конструктов, «заточенного» Келли на личность пациентов (или, как в нашем случае, персонажей художественного произведения).

\section{Семантическое пространство мотивации персонажей}

Другой формой, возможно, более адекватной для задачи понимания смысла фильма, является метод реконструкции мотивационной структуры персонажей фильма через декомпозицию целостного поведения на множество возможных мотивов поведения (см.: Петренко, 1983). Любой человеческий поступок является полимотивированным для самого субъекта, а также содержит множество мотивов, атрибутированных ему внешними наблюдателями и обстоятельствами. Используя значимость (желательность) объектов для индивида в текущий момент времени, мы можем рассчитать «мотивационный вектор» (Петренко, Супрун, 2012), построенный для любого условия. Данный вектор определяет мотив, которым руководствуется индивид, выбирая эти 
объекты в заданных условиях. Этим же вектором определяются и наиболее актуальные значения (интерпретации) объекта в данных условиях из всех возможных. Фактически мотивационный вектор совместно с состояниями объектов определяет психическое состояние индивида и его деятельность, направленную на удовлетворение актуальной потребности в данных условиях. Очевидно, что наиболее актуальными будут те значения объектов (или факторов, описывающих их в семантическом пространстве), которые максимально отвечают мотиву деятельности индивида в текущий момент.

Таким образом, выбор оптимального объекта $\mathbf{S}^{(\mathrm{k})}$ из всех возможных $(\mathrm{k}=$ $=1,2, \ldots, n)$ может быть осуществлен по признаку угловой близости его векторного семантического представления к мотивационному вектору М. Формально актуальность любого значения объекта можно определить как величину, пропорциональную косинусу угла $\alpha$ между направлениями мотивационного вектора $\mathbf{M}$ и вектора-описания объекта $\mathbf{S}^{(\mathrm{k})}$, который можно установить из определения скалярного умножения векторов $\mathbf{M} \cdot \mathbf{S}^{(\mathrm{k})} \cos \alpha$. Поскольку в семантическом пространстве все описания объектов нормируются к единице, то косинус $\alpha$ равен просто скалярному произведению $\mathbf{M} \cdot \mathbf{S}^{(\mathrm{k})}$ :

$$
\cos \alpha=\sum_{i=1}^{N} M_{i} S_{i}^{(k)},
$$

где $\mathrm{N}$ - число выделяемых факторов семантического пространства.

Знак скалярного произведения определяет знак пропозиции, а величина степень его смысловой значимости для индивида в субъективной интерпретации объекта в конкретных условиях. Таким образом, мотивационный вектор можно интерпретировать как фактор, обеспечивающий наилучшее соотношение свойств, удовлетворяющих некоторую потребность субъекта. Наибольшие компоненты $M_{i} S_{i}^{(k)}$ определяют значимость факторов в интерпретации объекта и представляют основной интерес субъекта в его целевом поведении.

Зависимость мотивационного вектора от актуального состояния субъекта и условий реализации потребности определяет изменчивость субъективного смысла объекта в отличие от его значений. Отметим, что именно цель, для которой используется данный объект, раскрывает его смысл (назначение) для субъекта.

Выше мы определили мотивационный вектор как фактор, обеспечивающий наилучшее соотношение свойств, удовлетворяющих некоторую потребность. Актуализированная потребность, выражающаяся в дефиците ресурсов, создает напряженность системы (биологической, психологической, социальной и пр.), стремящейся к компенсации этого дефицита. Таким образом, мы можем считать потребность (чья бы она ни была) реализованной, если результатом взаимодействия является некоторое ненапряженное стационарное состояние системы (Акофф, Эмери, 2008).

Категориальное же представление объектов определяет их значение, но не смысл, для раскрытия которого необходимо соотнести их с мотивом - некоторой целевой функцией исследуемой ментальности, определяющей их значимость 
для субъекта потребности. Таким образом, определив (оценив) рейтинги $R^{(\mathrm{k})}$ желательности возможных ситуаций, в которых субъект хотел бы оказаться (с минимальными статусными потерями, как в фильме «Расёмон»), мы можем определить и сам мотивационный вектор $\mathbf{M}$.

Поскольку значимость объектов для субъекта определяется соотношением (1), то очевидно, что она должна быть пропорциональна рейтингу этого объекта в оценках испытуемого. Следовательно,

$$
R^{(k)}=b \sum_{i=1}^{N} S_{i}^{(k)} M_{i}
$$

где b - некоторый коэффициент пропорциональности, определяемый из условий нормировки вектора М.

Решая систему из $n$ уравнений (2), можно получить идеальные соотношения свойств объекта, удовлетворяющего данную потребность в заданных условиях. Эти соотношения и определяют мотивационный вектор М. Очевидно, что каждый мотив в рамках конкретной ментальности детерминирован некоторой потребностью и конкретными условиями, в которых она должна реализовываться, т.е. сопоставлен с соответствующим мотивационным вектором М. Этот вектор характеризует оптимальное соотношение базовых свойств объекта для удовлетворения актуальной потребности в заданных условиях и выделяет (по характеру близости к нему) те наличные объекты и скрытые факторы, которые могут представлять для него интерес в данной ситуации.

Определив различные $\mathbf{M}_{\mathrm{j}}$ в актуальных состояниях, в дальнейшем с помощью факторного анализа можно построить мотивационное пространство субъекта (или выбранной ментальности) и получить разложение любого объекта не только в семантическом, но и в ортогонализованном мотивационном пространстве.

Это позволяет предсказывать желательность любого объекта по выборочным оценкам его свойств в заданных условиях и для исследуемой ментальности. Фактически мы получаем точное знание правил, по которым реализуется любое взаимодействие в исследуемой системе «субъект-объект». Используя формализованный метод мотивационной атрибуции, мы можем решить задачу, аналогичную той, с которой сталкивается следователь, пытаясь вычислить преступника, исходя из того, «кому это было выгодно», т.е. кто из подозреваемых был мотивирован на совершение преступления. В нашем подходе мы исходим из того, что вывод тем не менее всегда вероятностен. Ниже в качестве иллюстрации мы приводим реализацию метода атрибуции мотивов, рассматривая только два наиболее значимых мотивационных фактора. Целостное решение возможно в результате анализа многомерного мотивационного семантического пространства.

На рисунке 3 представлены векторы состояния персонажей фильма в семантическом пространстве при условии признания их показаний: $\mathbf{S}_{\mathbf{1}}(0.30$, $0.58), \mathbf{S}_{2}(0.51,-0.40), \mathbf{S}_{3}(0.60,0.30), \mathbf{S}_{4}(0.52,0.50)$. 
Рисунок 3

Мотивационное пространство персонажей фильма «Расёмон» по первым двум факторам

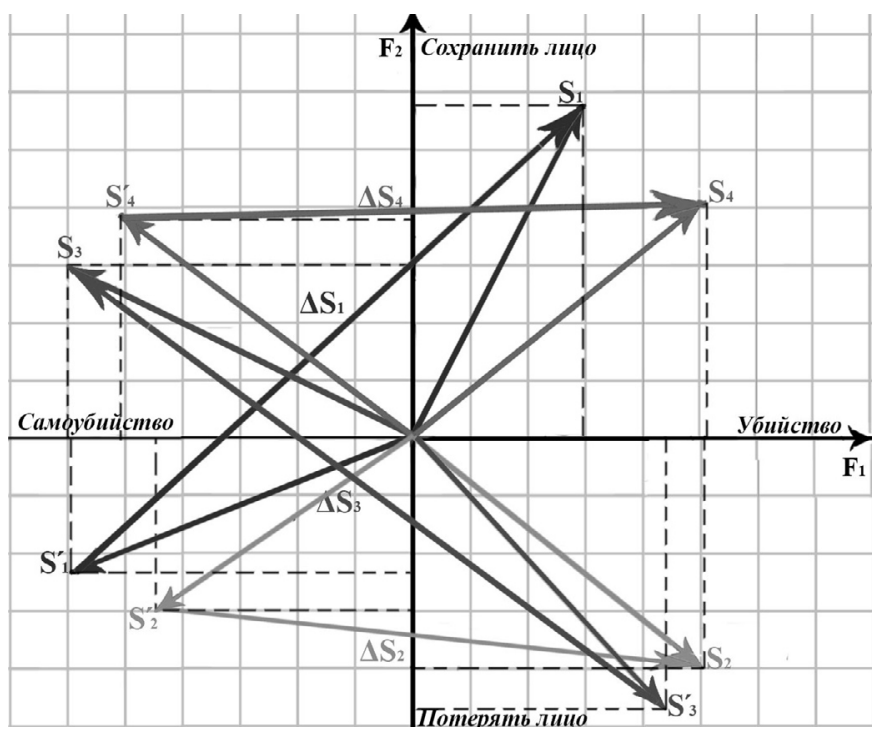

Примечание. $\mathrm{F}_{1}$ - фактор признания самоубийства или убийства самурая, $\mathrm{F}_{2}-$ фактор «сохранения лица» (социального статуса).

$\mathbf{S}_{1}{ }_{1}(-0.59,-0.24), \mathbf{S}_{2}(-0.45,-0.30), \mathbf{S}_{3}{ }_{3}(-0.44,-0.45), \mathbf{S}_{4}{ }_{4}(-0.51,0.49)-$ векторы состояния персонажей фильма в семантическом пространстве при условии смены их показаний на противоположные.

На рисунке 3 представлены: $\Delta \mathbf{S}_{1}, \Delta \mathbf{S}_{2}, \Delta \mathbf{S}_{3}, \Delta \mathbf{S}_{4}$ - векторы изменения состояний субъектов, фактически мотивационные векторы, отражающие стремление к признанию судом их показаний с целью повысить свой социальный статус.

\section{Описание изменения ситуации по $F_{2}$ (мотив «Сохранить лицо»)}

Свидетель $\mathbf{S}_{1}-$ смена показаний ведет к изменению статуса по $\mathbf{F}_{2}$ на $0.58-$ $(-0.24)=0.82$, т.е. от положительного до «потери лица».

Свидетель $\mathbf{S}_{2}$ - смена показаний ведет к ухудшению статуса по $\mathbf{F}_{2}$ на $-0.40-(-0.30)=-0.10$ («потеря лица»).

Свидетель $\mathbf{S}_{3}-$ смена показаний ведет к снижению статуса по $\mathbf{F}_{2}$ на $0.30-$ $(-0.45)=0.75$ (от положительного значения до «потери лица»).

Свидетель $\mathbf{S}_{4}-$ смена показаний практически не ведет к изменению статуса по $\mathbf{F}_{2}: 0.50-0.49=0.01$.

\section{Идентификащия персонажей}

В ситуации суда мы исходим из того, что каждый из героев фильма «Расёмон» выбирает для себя ту роль, которая минимизирует для него потерю социального статуса. 
Свидетель $\mathbf{S}_{4}-$ фактически для ситуации суда незаинтересованный свидетель, поскольку смена показаний не ведет к изменению его статуса по $\mathbf{F}_{2}$. Это крестьянин.

Свидетель $\mathbf{S}_{2}$ не заинтересован в улучшении своего статуса, т.е. он стремится своими показаниями нейтрализовать «потерю лица» кого-то другого за счет дальнейшего снижения своего отрицательного статуса. Даже опозоренная и потерявшая свой статус жена самурая, по обычаям средневековой Японии, обязана сохранять статус мужа. Своими показаниями она объясняет причину его смерти не поражением от разбойника, а своей местью. В любом случае после суда, по законам кодекса чести, жена обязана совершить сэппуку, поскольку только этим она может смыть свой позор.

Свидетель $\mathbf{S}_{3}-$ смена показаний этого свидетеля (от самоубийства до убийства) резко меняет положительный статус до «потери лица». Это характерно для самурая, поскольку только совершение сэппуку позволяет ему избежать позора от поражения в поединке с простолюдином.

Свидетель $\mathbf{S}_{1}-$ смена показаний этого свидетеля (от убийства самурая к его самоубийству) ведет к «потере лица». Этот вариант поведения подходит для разбойника, поскольку его в любом случае приговорят к смерти, но признание в убийстве самурая гарантирует ему определенную славу и повышение статуса.

Таким образом, мы получаем возможность через анализ мотивации персонажей идентифицировать авторство той или иной версии события (в нашем случае убийства или самоубийства самурая).

Дополнительный опрос о содержании и смысле художественного фильма «Расёмон» выявил отсутствие однозначной интерпретации. Приведем несколько примеров отзывов наших испытуемых.

1. Фильм, на мой взгляд, о человеческой слабости, каждый герой картины раскрывается нам не в самых своих лучших качествах, а также и о том, как далеко люди готовы зайти в своей лжи, пытаясь выставить определенную ситуацию в выгодном для них свете. Герои врали уже и сами себе, будучи не готовыми признать правду и увидеть истинную картину целиком. О том, кто же виновен на самом деле, мы, зрители, судить не можем уж точно, ну и, скорее всего, не это самое главное в этом фильме, не найти плохого героя, а понять, что в каждом человеке есть и добро и зло, вопрос лишь в том, какой сам человек делает выбор.

2. Фильм о том, что у каждого всегда своя правда, свое восприятие событий. Что нет объективного мира, он всегда ограничен нашим субъективным сознанием. Люди всегда стремятся к самооправданию, к попытке выглядеть лучше в чужих глазах, но в этом и проявляется их истинное Я. Ценности, убеждения и желания героев привели к трагическим событиям для каждого из них, и даже после этого люди пытались верить в свою правду и в свою невиновность. Мы никогда не можем быть ни в чем уверены полностью, потому что никто не знает, где есть та самая объективная реальность. В конце мы видим, как в человеке проявляется самое хорошее, что может в нем быть, мы видим искренность и свет солнца в конце тоннеля человеческой алчности, злости и обмана. 
3. Фильм повествует о судьбе 4 героев с 4 точек зрения на случившуюся трагедию. Каждый из 4 лиц рассказывает эту историю, опираясь на свое мнение, в силу этого зрителю тяжело понять, что все-таки произошло и кто виноват в преступлениях. Таким образом, можно сказать, что каждый из нас на одно событие смотрит совершенно по-разному, обращает внимание на абсолютно разные детали. Получается, что мы воспринимаем мир очень узконаправленно и субъективно, т.е. через призму своих собственных убеждений, ценностей и т.д. Поэтому сказать, КАКОЙ наш мир в объективной реальности, не представляется возможным. В связи с этим никогда не знаешь, кому можно верить. Намеренно или нет, человек искажает произошедшую историю. Отсюда и происходят все несправедливые события.

В конце фильма нам показывают сцену, в которой герои находят ребенка. И дровосек (рассказчик) забирает ребенка к себе, хотя дома уже шестеро детей. Это событие заставляет человека поверить в лучшее, в то, что люди могут еще друг другу доверять и рассчитывать на честность и другие хорошие поступки.

4. Фильм про то, что у каждого свое ви́дение реальности. Понятие «объективная реальность» - чисто абстрактное понятие. Ее как таковой не существует. Существует только субъективная реальность. Поэтому ответить на вопрос, кто убил самурая, на данный момент мне представляется невозможным.

5. Фильм о том, как 4 свидетеля выдают свою «правдивую» версию преступления, произошедшего в лесу, но рассказывают ее таким образом, что невозможно собрать картину воедино. Каждый из героев видит то, что хочет и чему хочет верить в силу своей нравственности. Фильм повествует о человеческой натуре - приукрашивать правду (факты) в свою пользу для защиты своей чести. В конце фильма заканчивается дождь, который смывает всю грязь и ложь человечества, что символизирует новый день, новое начало, новую жизнь.

6. Фильм о том, что у каждого человека есть своя правда, единой истины нет, поэтому есть сложности в межличностном, межгрупповом понимании в мире. Исходя из того, нельзя понять, кто убил самурая.

\section{Общее обсуждение}

Этот фильм вызвал сенсацию на Венецианском кинофестивале 1951 г., Куросава стал всемирно известным режиссером, обладателем премии Золотого Льва. В ряде рецензий на этот фильм обсуждается пристрастность человеческой натуры, которая препятствует поиску истины.

Пример одного из таких суждений: «Тогда как философы забавляются, утверждая, что существует множество истин, логика утверждает, что истина только одна, и, в силу этого, трое из дающих показания персонажей лгут. Так как интересы Куросавы лежат в первую очередь в изучении человеческой природы (а не в философии или повествовательной структуре), выходит, что "Расёмон" - лента не об истине, а о человеческой погрешимости, бесчестности и эгоизме» (Фалька, 2007). 
«Расёмон» - это тот редкий случай, когда кинолента перерастает свой обычный статус. Картина установила общекультурный язык для передачи расхожих понятий о взаимосвязи истины и недостоверности, о неизбежной субъективности, о памяти. В юридической сфере, например, адвокаты и судьи часто говорят об “эффекте Расёмона”, когда непосредственные свидетели преступления дают взаимоисключающие показания» (Принс, 2010). Аналогично в статье Е.Ф. Овчаренко (2018) «Расёмон-эффект» трактуется как следствие субъективности личностного восприятия, неполноты информации об объекте рассмотрения.

Но только ли констатацией пристрастности восприятия этот фильм возбудил мировую общественность? Мы видим в нем вариант вопроса, заданного в иной форме и в иной культуре, Иисусу Христу Понтием Пилатом: «В чем истина?» Фильм Куросавы, снятый по мотивам произведений Рюноске Акутагавы, на наш взгляд, ставит вопрос в несколько ином ракурсе: «А есть ли истина?»

Вопрос, возможно, вызовет недоумение у большей части читателей. Ведь кто-то нанес смертельный удар самураю! И квалифицированный следователь должен снять всякие субъективные моменты интерпретации очевидцев и выявить объективные доказательства по поводу того, кто совершил преступление, т.е. выяснить то, что В.М. Аллахвердов (см. дискуссию: Аллахвердов, 2005; Петренко, 2005) называет «то, что было на самом деле». С его точки зрения, Истина одна и не может иметь разночтений. Так, по крайней мере, полагает большинство зрителей, да и, наверно, доминирующее количество ученых. А.П. Назаретян именно в силу последнего утверждения назвал понятие «истина» «мифологическим» (Назаретян, 1995). Поясним свое понимание проблемы. Мы живем в релятивистском и вероятностном мире (см.: Петренко, Супрун, 2014), и, согласно конструктивистской теории Дж. Келли (2000), любой человек, познающий мир, строит альтернативные гипотезы, проверяемые как непротиворечивостью с его уже сложившейся моделью мира, так и практикой. Теории создаются на основе практики, но и практика наблюдения (на что направлено внимание исследователя) определяется его теоретической моделью. Представление о самореализующемся прогнозе, на мой взгляд, справедливо не только в социологии (Мертон, 2006), но и в целом в науке, в которой гипотезы о мире, пусть даже продемонстрировавшие свою несостоятельность, тем не менее влияют на формирование будущих моделей (хотя бы и через собственное отрицание). Вполне эвристичной (в плане устранения парадоксов наблюдения) представляется многомировая теория Хью Эверетта (см.: Дойч, 2018) о том, что мы живем в мультивселенной, где в результате каждого нашего действия рождается и ответвляется множество последовательных миров, в каждом из которых реализуется несколько иная версия мира и нас самих.

К тому же в классической рациональности присутствует слишком упрощенная версия причинности. В вышедшей в 1959 г. книге «Причинность и случайность в современной физике» Дэвид Бом трактует причинность, исходя из цельности, нелокальности и многомерности бытия: «Большинство следствий 
рассматривались как происходящие по одной или нескольким причинам. Бом, однако, почувствовал, что следствие может иметь за собой бесконечное множество причин. Например, если вы спросите, что вызвало смерть Авраама Линкольна, вам ответят, что это была пуля, вылетевшая из револьвера Джона Бута. Но полный список причин, за которым последовала смерть Линкольна, должен был бы включать все события, приведшие к производству данного оружия, все факторы, заставившие Бута желать смерти Линкольна, все шаги эволюционного развития человеческой расы и руки, способной удержать револьвер, и т.д. и т.п. Бом признавал, что в большинстве случаев можно игнорировать огромную вереницу причин, приводящих к конкретному следствию, но считал, что ученым очень важно помнить: ни одно из причинно-следственных отношений нельзя в действительности отделить от вселенной» (Талбот, 2004, c. 58).

Акцент настоящей статьи делается на релятивистской связи позиции наблюдателя (интерпретатора) события и характера данного им описания наблюдаемого события.

В качестве преамбулы последующего анализа расскажем буддийскую притчу. Путник подходит к чужой деревне. Навстречу ему выходит местный житель. Путник спрашивает его: «Какие люди живут в вашей деревне?» «А какие люди живут в вашей?» - вопрошает его местный житель. «О!» - отвечает путник. - «В нашей деревне живут очень добрые сердечные люди». «Раз так, говорит местный житель, значит, и в нашей деревне ты увидишь таких же добрых и сердечных людей.»

Эта притча иллюстрирует принцип релятивистской философии, согласно которому образ мира каждого человека индивидуален и зависит от ценностных установок, когнитивной сложности, системы ценностей, уровня интеллекта, степени духовности и еще множества иных когнитивных и эмоциональных параметров личности человека. «Мир как “местопребывание” четко коррелирует с уровнем развития сознания разных живых существ, и один и тот же мир в себе оказывается совершенно разными психокосмосами для разных живых существ. Как позднее скажет один махаянский мыслитель, то, что является рекой Ганг для человека, будет потоком гноя и нечистот для голодного духа и потоком амброзии для божества» (Торчинов, 2005, с. 53).

Но вернемся к интерпретации фильма и «Расёмон-эффекту». Даже для самого грамотного беспристрастного и квалифицированного следователя (или судьи) их заключение о предполагаемом убийце, с нашей точки зрения, не есть истина, а только возможная гипотеза, пусть и максимально правдоподобная. В своем заключении, отбирая доказательства, они опираются на вещественные артефакты преступления, свидетельства очевидцев, суждения о мотивах преступления и даже на такие современные технологии, как идентичность ДНК преступника и оставленных им биологических следов. В культуре и науке, построенных на субъект-объектной оппозиции, делается акцент на причинно-следственных связях. Каждое событие имеет свою причину, в классической рациональности независимую от исследователя. Но, согласно философии постнеклассической рациональности (Степин, 2006), происходит 
включение субъекта познания в единый познавательный контур с объектом познания, что и определяет производность картины мира не только от объекта, но и от субъекта познания, т.е. содержание «истины» определяется и позицией наблюдателя (исследователя). Все это не исключает иных маловероятных версий. Не случайно аргументом замены смертной казни на пожизненное заключение выступает именно потенциальная возможность судебной ошибки. Правда, разговор об ошибке судебного решения исподволь вводит представление о единственно правильном решении (т.е. об истине). Невозможно перестроить стиль мышления, заменив одно понятие (один термин). Ревизии необходимо подвергнуть, например, и понятие «объективная действительность», существующее как бы само по себе и независимое от позиции субъекта. Язык представляет собой сложную развивающуюся систему, и перестройка менталитета требует системной перестройки всего понятийного аппарата.

Проблематика истины и «Расёмон-эффект» выглядят еще сложнее и многомернее применительно к ценностным трактовкам событий в истории. Исследователи с различной системой ценностей могут по-разному оценивать эти события. Так что́ из этого следует - безбрежный релятивизм по принципу «И ты прав, и ты прав»? Отнюдь нет, но в вероятностную модель реконструкции происшедшего события необходимо введение системы ценностей и мотивов участников, культурно-исторической специфики их менталитета. Применительно к интерпретации фильма А. Куросавы «Расёмон» сто́ит вспомнить о традиции японского дзен-буддизма как ветви великой культуры буддизма.

В отличие от европейской трактовки «истины» как соответствия представлений чему-то объективному, существующему помимо познающего субъекта, буддийская традиция снимает «субъект-объектную оппозицию» и проповедует идею «недвойственности» как единства познающего и познаваемого (см.: Торчинов, 2005; Карицкий, 2010). Сошлюсь на мнение известного специалиста в области трансперсональной психологии, измененных состояний сознания и психологии буддизма, индуизма, шаманизма В.В. Козлова, не только изучавшего буддийские психотехники с помощью сакральных текстов, но и переживавшего их в собственной многолетней практике: «Эту истину всякий просветленный осознает внутри себя, и она является для него единственной реальностью, или нирваной, а все остальное - лишь иллюзия» (Козлов, 2016, с. 122).

В этом контексте буддийской культуры каждый свидетель - участник гибели самурая по-своему искренен, его версия происшествия может быть «правдива» (в его мировосприятии или, как сказали бы физики, в его системе отсчета). Другое дело, что, не будучи просветленными, они созерцают наличную ситуацию через призму собственной пристрастности. Но возможна ли в рамках этого мира беспристрастность?

Согласно буддизму, корень страдания лежит во влечениях и страстях. Реализуя призыв отсечь этот корень, чтобы избежать страданий, не отсекаем ли мы человеческую культуру, где все пронизано страстями? С идеями буддизма перекликается и христианское мировосприятие. «Не что есть истина, а 
кто есть истина» - отмечает Ю.А. Шрейдер (1992), подчеркивая личностный аспект этой проблемы. «Аз есмь путь, истина и живот (жизнь). Никто не придет к Отцу, кроме как через Меня» (Ин 14:6) - утверждал Иисус. Такая позиция переносит проблему истины в этическую плоскость (см.: Гусейнов, 1995). Ведь, согласно логике, пересказ, например, таблицы умножения есть изречение истин. Но много ли стоит такое понимание истины? В конце фильма «Расёмон» происходит столкновение поступков персонажей: вора-провокатора, укравшего пеленки подброшенного младенца, и дровосека, забравшего в свою семью обреченного на смерть ребенка. Куросава, на наш взгляд, дает свою версию истины как формы духовного состояния человека, где критерием выступает выбор сердцем. Выбор сердцем, на наш взгляд, определен этикорелигиозной логикой очеловечивания бытия и, в свою очередь, обусловлен глобальной космической эволюцией (Федоров, 1982; Циолковский, 2015; Померанц, 1998; Моисеев, 2000; Назаретян, 2017).

Учет субъектности не как артефакта пристрастности, а как существенного компонента в построении модели мира еще нуждается в своем развитии, хотя имеются и существенные сдвиги в решении этой проблемы, в частности, в психологии (Рубинштейн, 1977; Абульханова-Славская, 1991; Брушлинский, 1994; Петренко, Супрун, 2014). Уже в современной судебной практике учитываются мотивы деяния, а не только сам факт произошедшего в «объективной действительности». Не случайно в русском языке разводятся понятия «истина» и «правда» (Знаков, 1999), хотя и последнему понятию подчас приписывается однозначность. «Правда всегда одна - наша» (из агитационного ролика КПР). Никто в этом мире не лицезреет истину как кантовскую «вещь в себе» и ограничен своей «картиной мира». Прошлое - всегда только некая «картина прошлого», пусть и свершившегося только минуту тому назад.

История не застывший слепок прошлого, а живая развивающаяся и многоальтернативная модель прошедшего, требующая активной и пристрастной реконструкции, включающей саморефлексию вследствие неустранимости субъекта познания из самого познания (Петренко, 2018). Постановка в художественной форме вопроса о реконструкции прошлого в фильме Акиры Куросавы вызвала столь жгучий интерес у думающей публики именно в силу интуитивного осознания иллюзорности наших трактовок действительности и необходимости новых версий познания прошлого как одного из базисных экзистенциональных понятий. Перенос феномена «Расёмон-эффекта» в область этики, идеологии и политики еще раз ставит проблему истины применительно к мировосприятию пристрастного, эмоционально включенного и экзистенционально заинтересованного мировосприятия человека-субъекта.

\section{Литература}

Абульханова-Славская, К. А. (1991). Стратегия жизни. М.: Мысль.

Аллахвердов, В. М. (2005). Блеск и нищета эмпирической психологии. Психология. Журнал Высшей школы экономики, 2(1), 44-65. 
Акофф, Р., Эмери, Ф. (2008). О иелеустремленных системах. М.: УРСС.

Бом, Д. (1959). Причинность и случайность в современной физике. М.: Иностранная литература. Брушлинский, А. В. (1994). Проблемы психологии субъекта. М.: Институт психологии РАН.

Грачева, А. М., Нистратов, А. А., Петренко, В. Ф., Собкин, В. С. (1988). Психосемантический анализ понимания мотивационной структуры поведения киноперсонажа. Вопросы психологии, 5, 123-131.

Гусейнов, А. А. (1995). Великие моралисты. М.: Республика.

Дойч, Д. (2018). Структура реальности. Наука параллельных вселенных (3-е изд.). М.: Альпина нон-фикшн.

Знаков, В. В. (1999). Психология понимания правды. СПб.: Алетейя.

Карицкий, И. Н. (2010). Понятие субъекта и объекта в философии и психологии. Методология и история психологии, 5(1), 69-101.

Келли, Дж. А. (2000). Психология личности. Теория личных конструктов. СПб.: Речь.

Козлов, В. В. (2016). Психология буддизма: четвертое колесо дхармы (2-е изд., испр. и доп.). Вологда: Древности Севера.

Мертон, Р. К. (2006). Социальная теория и социальная структура. М.: АСТ /Хранитель.

Моисеев, Н. Н. (2000). Судъба цивилизации. Путь разума. М.: Языки русской культуры.

Назаретян, А. П. (1995). Истина как категория мифологического мышления. Общественные науки и современность, 4, 105-108.

Назаретян, А. П. (2017). Нелинейное будущее. Мегаистория, синергетика, культурная антропология и психология в глобальном прогнозировании (4-е изд.). М.: Аргамак-Медиа.

Овчаренко, Е. Ф. (2018). «Расёмон-эффект» как феномен коммуникативной дезориентации (опыт медиаисследования). Концепт: философия, религия, культура, 1, 129-141.

Окунь, Я. (1974). Факторный анализ. М.: Статистика.

Петренко, В. Ф. (1983). Психосемантическое исследование мотивации. Вопросы психологии, 3 , $29-39$.

Петренко, В. Ф. (2005). Что есть истина (или наш ответ лорду Чемберлену). Психология. Журнал Высшей школь экономики, 2(1), 93-101.

Петренко, В. Ф. (2013). Многомерное сознание: психосемантическая парадигма (2-е изд., доп.). М.: Эксмо.

Петренко, В. Ф. (2018). Конструирование истории. Методология и история психологии, 1, 15-33.

Петренко, В. Ф., Алиева, Л. А., Шеин, С. А. (1982). Психосемантические методы исследования оценки и понимания кинопроизведения. Вестник Московского университета. Серия 14. Психология, 2, 13-21.

Петренко, В. Ф., Дедюкина, Е. А. (2017). Психосемантический анализ художественного фильма. В кн. Перспективы психологической науки и практики: сборник статей Международной научно-практической конференции (с. 501-507). М.: ФГБОУ ВО «РГУ им. А.Н. Косыгина».

Петренко, В. Ф., Дедюкина, Е. А. (2018). Поиск смысла собственного существования (на материале восприятия и понимания художественного фильма). Вестник Московского университета. Серия 14. Психология, 4, 54-73.

Петренко, В. Ф., Сапсолева, О. Н. (2005). Психосемантический анализ художественного фильма «Сибирский цирюльник». Вопросы психологии, 1, 56-72.

Петренко, В. Ф., Супрун, А. П. (2012). Целеустремленные системы. Эволюция и субъектный аспект системологии. Труды Института системного анализа Российской академии наук, $62(1), 3-25$. 
Петренко, В. Ф., Супрун, А. П. (2014). Взаимосвязь квантовой физики и психологии сознания. Психологический журнал, 35(6), 69-86.

Померанц, Г. С. (1998). Страстная односторонность и бесстрастие духа. М.: Университетская книга.

Рубинштейн, С. Л. (1977). Человек и мир. М.: Наука.

Степин, В. С. (2006). Философия науки. Общие проблемы. М.: Гардарики.

Принс, С. (2010, 1 ноября). Эссе о фильме «Расёмон». Режим доступа: https://text.3dn.ru/publ/ iskusstvo/o_filme_quot_rasjomon_quot_akiry_kurosavy/9-1-0-70

Талбот, М. (2004). Голографическая Вселенная. М./Киев: София.

Торчинов, В. Н. (2005). Введение в буддизм. СПб.: Амфора.

Фалька. (2007, 12 октября). Расемон/Rashomon [Пост в «Живом журнале»]. Режим доступа: https://kultovoe-kino.livejournal.com/314688.html?view=comments

Федоров, Н. Ф. (1982). Сочинения. М.: Мысль.

Циолковский, К. Э. (2015). Воля Вселенной. Космическая философия. М.: Эксмо.

Шрейдер, Ю. А. (1992). Семиотика молитвы. Социальная и философская мысль (Киев), 5, 50-63.

Петренко Виктор Федорович - заведующий лабораторией, лаборатория «Психология общения и психосемантика», факультет психологии, Московский государственный университет имени М.В. Ломоносова, член-корр. РАН, профессор МГУ.

Сфера научных интересов: психосемантика сознания, проблемы бессознательного, общая психология, методология психологии, семиотика, психология искусства, политическая психология, измененные состояния сознания.

Контакты: victor-petrenko@mail.ru

Супрун Анатолий Петрович - старший научный сотрудник, лаборатория «Психология общения и психосемантика», факультет психологии, Московский государственный университет имени М.В. Ломоносова, кандидат психологических наук, доцент.

Сфера научных интересов: психосемантика сознания, проблемы бессознательного, общая психология, методология психологии, семиотика, психофизиология.

Контакты: anatoly.suprun@gmail.com

Кодирова Шарифахон Асратуллоевна - докторант, Академия государственного управления при Президенте Республики Узбекистан.

Сфера научных интересов: психосемантика, организационная психология, психология переговоров.

Контакты: A.sharifa_k_93@mail.ru 


\title{
Psychosemantic Analysis of Akira Kurosawa's Feature Film "Rashomon"
}

\author{
V.F. Petrenko ${ }^{a}$, A.P. Suprun ${ }^{a}$, S.A. Kodirova ${ }^{b}$ \\ ${ }^{a}$ Lomonosov Moscow State University, 1 Leninskie Gory, Moscow, 119991, Russian Federation \\ ${ }^{b}$ Academy of Public Administration under the President of the Republic of Uzbekistan, 45 Islam Karimov \\ Str., Tashkent, 100066, Uzbekistan
}

\begin{abstract}
This article is devoted to the psychosemantic analysis of the feature film Rashomon by the Japanese director Akira Kurosawa, based on the stories In a Thicket and Rashomon Gate by Ryunosuke Akutagawa. Scientific ideas in various forms often emerge at the level of the collective and individual unconscious. So, the creator of the theory of relativity, Albert Einstein, noted that the novel by F.M. Dostoevsky The Brothers Karamazov became for him a creative analogue of the theory of relativity. According to the concept of "polyphonism," introduced by M.M. Bakhtin, the voices of Dostoevsky's characters act as independent reference systems that bear their truth to life. Similarly, in A. Einstein's theory, the parameters of the observed object depend on the position of the observer, and there is no "correct" description "outside" of this position. N. Bohr believed that both the studied phenomenon and its observer cannot be attributed to independent physical reality. In the Everett (multi-world) interpretation of quantum mechanics, the concept of a correlated state ("relative state") that occurs when observing a quantum system is introduced. H. Everett believed that the result of its observation is not a "mystical" reduction of all possibilities to the only one, but a splitting of reality into many worlds, where one of these possibilities is realized. Now in the everettics it is believed that the result of the observation is an alterverse - a certain set of states where a single reality is observed from various "points of view." Note that Socrates also showed the conventionality or relativity of any empirical knowledge of the world. Forcing the interlocutors to apply "common" concepts to various objects, he caused them to come to understanding that these objects become illusory, that is, they do not correspond to these "single" concepts. Our interest in the problem of how the position of observers influences the reality they design is reflected in a series of publications on this topic. And in this context, we were attracted to the film Rashomon, where the ideas of relativism are contrastingly presented in the artistic form.
\end{abstract}

Keywords: cinematography, psychosemantics, semantic spaces, multidimensional truth, relativism.

\section{References}

Abul'khanova-Slavskaya, K. A. (1991). Strategiya zhizni [Life strategy]. Moscow: Mysl'. (in Russian) Ackoff, R. L., \& Emery, F. E. (2008). O tseleustremlennykh sistemakh [On purposeful systems]. Moscow: URSS. (in Russian; transl. of: Ackoff, R. L., \& Emery, F. E. (1972). On purposeful systems: An interdisciplinary analysis of individual and social behavior as a system of purposeful events. Chicago, IL: Aldine-Atherton.) 
Allakhverdov, V. (2005). Blesk i nishcheta empiricheskoy psikhologii (Na puti k metodologicheskomu manifestu peterburgskikh psikhologov) [Splendour and misery of empirical psychology: towards a methodological manifesto of petersburgian psychologists]. Psychology. Journal of Higher School of Economics, 2(1), 44-65. (in Russian)

Bohm, D. (1959). Prichinnost' i sluchainost'v sovremennoi fizike [Causality and chance in modern physics]. Moscow: Inostrannaya literatura. (in Russian; transl. of: Bohm, D. (1957). Causality and chance in modern physics. London: Routledge and Paul.)

Brushlinskii, A. V. (1994). Problemy psikhologii sub"ekta [Issues of the subject's psychology]. Moscow: Institute of Psychology of the RAS. (in Russian)

Deutsch, D. (2018). Struktura real'nosti. Nauka parallel'nykh vselennykh [The structure of reality. A science of parallel universes] (3rd ed.). Moscow: Al'pina non-fikshn. (in Russian; transl. of: Deutsch, D. (1997). The fabric of reality. New York: Viking Adult.)

Falka. (2007, October 12). Расемон/Rashomon [Post]. Retrieved from https://kultovoe-kino.livejournal.com/314688.html?view $=$ comments (in Russian)

Fedorov, N. F. (1982). Sochineniya [Works]. Moscow: Mysl'. (in Russian)

Gracheva, A. M., Nistratov, A. A., Petrenko, V. F., \& Sobkin, V. S. (1988). Psikhosemanticheskii analiz ponimaniya motivatsionnoi struktury povedeniya kinopersonazha [Psychosemantic analysis of understanding the motivational structure of behavior of a movie character]. Voprosy Psikhologii, 5, 123-131. (in Russian)

Guseinov, A. A. (1995). Velikie moralisty [The great moralists]. Moscow: Respublika. (in Russian)

Karitskii, I. N. (2010). Ponyatie sub"ekta i ob”ekta v filosofii i psikhologii [The concept of the subject and the object in philosophy and psychology]. Metodologiya i Istoriya Psikhologii [Methodology and History of Psychology], 5(1), 69-101. (in Russian)

Kelly, G. A. (2000). Psikhologiya lichnosti. Teoriya lichnykh konstruktov [A theory of personality. The psychology of personal constructs]. Saint Petersburg: Rech'. (in Russian; transl. of: Kelly, G. (1963). A theory of personality. The psychology of personal constructs. New York: Norton.)

Kozlov, V. V. (2016). Psikhologiya buddizma: chetvertoe koleso dkharmy [The psychology of Buddhism: The fourth wheel of Dharma] (2nd ed.). Vologda: Drevnosti Severa. (in Russian)

Lotman, Yu. M. (1973). Semiotika kino i problemy kinoestetiki [Semiotics of films and issues of film aesthetics]. Tallinn: Eesti raamat. (in Russian)

Merton, R. K. (2006). Sotsial'naya teoriya i sotsial'naya struktura [Social theory and social structure]. Moscow: AST/Khranitel'. (in Russian; transl. of: Merton, R. K. (1968). Social theory and social structure. New York: The Free Press.)

Moiseev, N. N. (2000). Sud'ba tsivilizatsii. Put' razuma [The fate of civilization. The way of reason]. Moscow: Yazyki russkoi kul'tury. (in Russian)

Nazaretyan, A. P. (1995). Istina kak kategoriya mifologicheskogo myshleniya [Truth as a category of mythological thinking]. Obshchestvennye Nauki i Sovremennost', 4, 105-108. (in Russian)

Nazaretyan, A. P. (2017). Nelineinoe budushchee. Megaistoriya, sinergetika, kul'turnaya antropologiya i psikhologiya v global'nom prognozirovanii [The non-linear future. Megahistory, synergetics, cultural anthropology and psychology in global forecasting] (4th ed.). Moscow: Argamak-Media. (in Russian)

Okun', Ya. (1974). Faktornij analiz [Factor analysis]. Moscow: Statistika. (in Russian)

Ovcharenko, E. F. (2018). "Rashomon effect" as a communicative disorientation phenomenon (mediaresearch essay). Kontsept: Filosofiya, Religiya, Kul'tura [Concept: Philosophy, Religion, Culture], 1, 129-141. (in Russian) 
Petrenko, V. (2005). Chto est' istina? [What is truth? Our response to the Lord Chamberlain]. Psychology. Journal of Higher School of Economics, 2(1), 93-101. (in Russian)

Petrenko, V. F. (1983). Psikhosemanticheskoe issledovanie motivatsii [A psychosemantic study of motivation]. Voprosy Psikhologii, 3, 29-39. (in Russian)

Petrenko, V. F. (2013). Mnogomernoe soznanie: psikhosemanticheskaya paradigma [Multidimensional consciousness: A psychosemantic paradigm] (2nd ed.). Moscow: Eksmo. (in Russian)

Petrenko, V. F. (2018). Construction of history. Metodologiya i Istoriya Psikhologii [Methodology and History of Psychology], 1, 15-33. (in Russian)

Petrenko, V. F., \& Dedyukina, E. A. (2017). Psikhosemanticheskii analiz khudozhestvennogo fil'ma [A psychosemantic analysis of a feature film]. In Perspektivy psikhologicheskoi nauki i praktiki: sbornik statei Mezhdunarodnoi nauchno-prakticheskoi konferentsii [Perspectives of psychological science and practice: proceedings from an international research-to-practice conference] (pp. 501-507). Moscow: Russian State University im. A.N. Kosygina. (in Russian)

Petrenko, V. F., Alieva, L. A., \& Shein, S. A. (1982). Psikhosemanticheskie metody issledovaniya otsenki i ponimaniya kinoproizvedeniya [Psychosemantic methods of study of how to assess and understand a film]. Moscow University Psychology Bulletin, 2, 13-21. (in Russian)

Petrenko, V. F., \& Dedyukina, E. A. (2018). Search for the meaning of one's own existence (based on the perception and understanding of the film). Moscow University Psychology Bulletin, 4, 54-73. (in Russian)

Petrenko, V. F., \& Sapsoleva, O. N. (2005). A psychosemantic analysis of the film "The barber of Siberia”. Voprosy Psikhologii, 1, 56-72. (in Russian)

Petrenko, V. F., \& Suprun, A. P. (2012). Tseleustremlennye sistemy. Evolyutsiya i sub”ektnyi aspekt sistemologii [The goal-oriented systems. Evolution and subjective aspect of systemology]. Trudy Instituta Sistemnogo Analiza Rossiiskoi Akademii Nauk, 62(1), 3-25. (in Russian)

Petrenko, V. F., \& Suprun, A. P. (2014). Correlation between quantum physics and psychology of consciousness. Psikhologicheskii Zhurnal, 35(6), 69-86. (in Russian)

Pomerants, G. S. (1998). Strastnaya odnostoronnost' i besstrastie dukkha [Passionate one-sidedness and a dispassionate spirit]. Moscow: Universitetskaya kniga. (in Russian)

Prince, S. (2010, November 11). Esse o fil'me "Rashomon" [About the film "Rashomon"]. Retrieved from https://text.3dn.ru/publ/iskusstvo/o_filme_quot_rasjomon_quot_akiry_kurosavy/9-1-070 (in Russian)

Rubinstein, S. L. (1977). Chelovek i mir [A man and the world]. Moscow: Nauka. (in Russian)

Shreider, Yu. A. (1992). Semiotika molitvy [Semiotics of a prayer]. Sotsial'naya i Filosofskaya Mysl' (Kiev), 5, 50-63. (in Russian)

Stepin, V. S. (2006). Filosofiya nauki. Obshchie problemy [The philosophy of science. General issues]. Moscow: Gardariki. (in Russian)

Talbot, M. (2004). Golograficheskaya Vselennaya [The holographic universe]. Moscow/Kiev: Sofiya. (in Russian; transl. of: Talbot, M. (1991). The holographic universe. New York: HarperCollins.)

Torchinov, V. N. (2005). Vvedenie v buddizm [Introduction to Buddhism]. Saint Petersburg: Amfora. (in Russian)

Toynbee, A. J. (1976). Mankind and mother earth. A narrative history of the world. New York/London: Oxford University Press.

Tsiolkovskii, K. E. (2015). Volya Vselennoi. Kosmicheskaya filosofiya [The will of the universe. Cosmic philosophy]. Moscow: Eksmo. (in Russian) 
Znakov, V. V. (1999). Psikhologiya ponimaniya pravdy [The psychology of understanding truth]. Saint Petersburg: Aleteiya. (in Russian)

Viktor F. Petrenko - Head of the laboratory "Psychology of Communication and Psychosemantics", Department of Psychology, Lomonosov Moscow State University, member of the Russian Academy of Sciences, professor of Lomonosov Moscow State University, DSc in Psychology.

Research Area: psychosemantics of consciousness, problems of unconscious, general psychology, methodology of psychology, semiotics, psychology of art, political psychology, altered states of consciousness.

E-mail: victor-petrenko@mail.ru

Anatoly P. Suprun - Senior Research Fellow, laboratory "Psychology of Communication and Psychosemantics", Department of Psychology, Lomonosov Moscow State University, PhD in Psychology, associate professor.

Research Area: psychosemantics of consciousness, problems of unconscious, general psychology, methodology of psychology, semiotics, psychophysiology.

E-mail: anatoly.suprun@gmail.com

Sharifakhon A. Kodirova - doctoral student, Academy of Public Administration under the President of the Republic of Uzbekistan.

Research Area: psychosemantics, organizational psychology, psychology of negotiations.

E-mail: A.sharifa_k_93@mail.ru 